\title{
Influence des tanins hydrolysables de châtaignier sur le métabolisme azoté des ovins et des caprins
}

\author{
N Zimmer, R Cordesse, M Inesta, D Fabre \\ ENSA-INRA, UZM, place Viala, 34060 Montpellier Cedex 1, France
}

Les tanins ont la propriété de se complexer aux protéines. Ceci peut conduire à l'insolubilisation de protéines alimentaires et à l'inhibition d'enzymes digestives. L'objectif de ce travail est d'étudier les effets de l'ingestion de tanins sur le métabolisme azoté des ovins et caprins.

Des tanins hydrolysables sont solubilisés et pulvérisés sur un foin de Crau $(F)$. Le régime riche en tanins ( $10 \%$ de la MS : FT) et le régime témoin ( $F$ ) apportent la même quantité de MS de foin équivalente à $28 \mathrm{~g} \mathrm{MOD} / \mathrm{j} / \mathrm{kg} P^{0.75}$. La ration est distribuée en un seul repas. Ces régimes sont testés, en carré latin, sur 6 chèvres du Rove et 6 moutons Mérinos d'Arles. La moitié des animaux porte une canule au niveau du rumen. Après 2 semaines d'adaptation, la digestibilité de l'azote est mesurée. Des cinétiques de dégradabilité in sacco de 2 substrats tannés et non tannés (F et FT ; tourteau d'arachide tanné, AT, et non tanné, A) sont réalisées ainsi que l'évolution, au cours de la journée, du $\mathrm{pH}$ et de la teneur en $\mathrm{NH}_{3}\left(\left[\mathrm{NH}_{3}\right]\right)$ du jus de rumen. La concentration de l'urée ([urée]) dans le plasma est dosée à jeun.

Le tannage du foin du régime ( $F T$ vs $F$ ) entraîne une augmentation de l'azote fécal et une diminution du CUD apparent de l'azote, confirmant les résultats obtenus avec d'autres tanins (Mc Leod, 1974, Nutr Abstr Rev, 44, 803-815).

La dégradabilité in sacco de substrats tannés ou non, riches en cellulose ( $F, F T$ ) ou en protéines $(A, A T)$ met en évidence :

- pour un régime donné ( $F$ ou FT), une vitesse de dégradation significativement plus faible pour AT que pour A : la valeur " $c$ " (d'après l'équation d'Orskov et Mc Donald (1979, J Agric Sci Camb, 92, 499-503)) diminue de $49 \%(P<0,0001)$. Le potentiel de dégradation est cependant inchangé,

- pour un substrat donné tanné (FT ou AT) ou non ( $F$ ou $A$ ), des potentiel et vitesse de dégradation identiques quel que soit le régime (F ou FT).

Les évolutions des $\mathrm{pH}$ et $\left[\mathrm{NH}_{3}\right]$ sont résumées dans le tableau. Pour un régime donné, l'évolution du $\mathrm{pH}$ après le début du repas est semblable pour les 2 espèces animales. Sur $\mathrm{FT}$, le $\mathrm{pH}$ minimal est atteint $1 \mathrm{~h}$ après le début du repas contre $9 \mathrm{~h}$ sur $\mathrm{F}$. Concernant la $\left[\mathrm{NH}_{3}\right]$, quels que soient le régime et l'espèce animale, le minimum est atteint au moins $9 \mathrm{~h}$ après le début du repas.

Les tanins agiraient directement sur les protéines alimentaires en diminuant leur accessibilité aux hydrolases. Ceci expliquerait la moindre digestibilité de l'azote.

La présence de ces tanins dans l'aliment ne modifierait pas les capacités cellulolytiques et protéasiques de la flore du rumen.

Chez les ovins, les tanins abaissent le niveau, à jeun, des métabolites facilement utilisables : $\left[\mathrm{NH}_{3}\right.$ ] dans le rumen et [urée] du plasma $(270 \mathrm{mg} / \mathrm{l} \pm 53$ sur $\mathrm{FT}$ contre $402 \pm 39$ sur $\mathrm{F}$, $P<0,0001)$; ces diminutions ne semblent pas affecter l'état général des animaux.

\begin{tabular}{|c|c|c|c|c|c|}
\hline régime & & F ovins & F caprins & FT ovins & FT caprins \\
\hline \multirow[t]{2}{*}{$\mathrm{pH}$} & à jeun & \multicolumn{2}{|c|}{$7,0 \pm 0,1^{a}$} & \multicolumn{2}{|c|}{$7,0 \pm 0,1^{a}$} \\
\hline & minimum & \multicolumn{2}{|c|}{$6,0 \pm 0,2^{a}$} & $6,3 \pm 0,1^{b}$ & $6,5 \pm 0,1^{c}$ \\
\hline \multirow[t]{2}{*}[\mathrm{NH}_{3}]{$(\mathrm{mg} / \mathrm{l})$} & à jeun & $221 \pm 28$ & $200 \pm 25^{b}$ & $74 \pm 41^{c}$ & $162 \pm 38^{b}$ \\
\hline & minimum & $43 \pm 25^{a}$ & $22 \pm 14^{a}$ & $30 \pm 10^{a}$ & $31 \pm 3^{a}$ \\
\hline
\end{tabular}

$a, b, c$ : dans la même ligne, les valeurs avec une lettre identique sont non significativement différentes à $P<0,05$. 